\title{
The role of urban sculpture in shaping the meaning of identity in contemporary urban planning
}

\author{
Elham Shahhosseini \\ Sama Technical and Vocational Training College, Islamic Azad University Kerman Branch, Kerman, Iran
}

Email address:

Shahhosseini.704@gmail.com

To cite this article:

Elham shahhosseini. The Role of Urban Sculpture in Shaping the Meaning of Identity in Contemporary Urban Planning. International Journal of Science, Technology and Society. Special Issue: Research and Practice in Architecture and Urban Studies in Developing Countries. Vol. 3, No. 2-1, 2015, pp. 24-26. doi: 10.11648/j.ijsts.s.2015030201.15

\begin{abstract}
In order to investigate the role of urban sculpture in shaping the sense of identity in contemporary urbanism, studying their history and background and reasons for their emergence in the city seem to be necessary. The emergence of the identity crisis may be a predisposing factor for authentication attempts. Location is an aspect of space which is occupied by something or someone and has meaning and value dimensions. In other words, location is where function and meaning of space interact. Thus, form, function, installation place and connotation of urban sculpture can have a central role for formation and alignment of existent semantic identity of urban planning of a city. The goal of this study is to study the role of these statues in the sense of identity in urban planning and the research method was literature review and surveying. The results show that the statues have a major role to stabilize or disrupt the meaning of identity in a city.
\end{abstract}

Keywords: Urban Sculpture, Identity, Meaning, Urbanism

\section{Introduction}

One of the most important functions of urban sculpture is creating a defined sense of place, induce a specific spirit to the space or reinforce sense of space. The place is a portion of the space which is occupied by someone or something and its meaning is valuable. In condition of existing a harmony between the statue and the environment and enhancing the visual integrity of the environment, citizens feel satisfaction and greater comfort and sense of place will be enhanced. Identity is another important factor in contemporary urban studies. The identity includes a certain range. A range that an individual using it, can recognize or distinguish a place from other places so that find a unique personality or at least specific personality for itself. Hence, it can be said that statues which enjoy creative and artistic design can make identity but to achieve the principles of identity, the issues of identity and meaning should be explored more.

\section{Identity and Spiritual Identity}

Identity is one of most controversial issues of the present age and everyone have a kind of identity concerns, but most discussions instead of realizing the issue and finding a feasible way to resolve it, just reflect this concern. Although this reflections in turn is essential but if do not lead to practical solutions to deal with the problem, in practice, don't have any result except arouse anxiety and denial of confidence between them. In fact, the identity is a response to what and who questions (Sajjadi, 2002).

Emergence of identity crisis may be a predisposing factor for authentication attempts. The result of identity confirmation and authentication is spiritual identity of measured space from the perspective of person and community and its necessity is a situation which may provide spiritual identity for space. With the recognition of this condition, it is possible to direct a space where affected by identity crisis to the desired authentication and during changes, preserve the identity-full space from identity crisis. On the other hand, this should be considered that the identity gets its validity from recognizable being. Thus, the most important condition for spiritual identity, is recognizable being. Meanwhile, the recognizable affairs are space, diagnostic criteria, mental image and the space's closeness to expectations (Ghasemi, 2004). 


\section{Space, Form, Function: Identity, Rootlessness}

Wherever the identity-full space is discussed, in fact, place is the subject. The place is a portion of the space which is occupied by someone or something and its meaning is valuable. In other words, the place is where function and meaning of space interact. The first consequence of the identity crisis is that the person finds himself rootless. The reason of this rootedness can be searched in a distorted sense of place. Consequently, place identity is composed and person does not know himself as belonging to a particular location anymore and therefore feels rootlessness.

Distortions of local identity can lead to lack of identity for person and rootlessness causes separation from the place. About the discussion of national and cultural identity in Iran, this nation before Islam, for a long time was a feudal land, namely in each district a lineage or kingdom clan was dominant. Naturally, national identity, when overwhelmed by vision and ideas and philosophy or political expediency, is not constant and evolves due to the time change (Sattari, 2003).

\section{Meaning and Semiotics in Urban Planning}

Art, as offers the basic definition of the nature of public space, makes citizens, who have not any knowledge about their surrounding and its rapid changes, aware with all its power and by the mobilization of general emotional reactions, shows the city as an asset which requires protection against intrusion. In this way, Public space becomes a territory to explore identity and reduce pressures of modern life in the shadow of historic landmarks (Verlag, 1997). Urban planners can emphasize on steering and directing the changes to the meaningful environment, people and their environment and/or both of them. Designers must not ignore teaching people that is extremely effective to understand and use the characteristics of their environments in a better way. A successful urban design requires satisfying of human behavior values. In fact, an urban designer should know what people know, what people celebrate, what people remember and what they remind which relate to the symbolic, cultural, historic and meaning aspects of urban spaces (Bahraini, 2008). sometimes Urban sculpture can act like symbols. Symbols usually predominate the surrounding area, with their effective size and shape. Thus, they can be used as a basis for orientation of all aspects. Specific characteristics of the sign, it is unique, which is exclusive and memorable in the minds of visitors. If the symbols have obvious form and conflict with their field or their position dominate around, It is easy to recognize (Lynch, 1960). In this regard, it should be noted that signs and symbols are rather random. Physical manifestations are not brand or mark but are merely potential tools to convey the meaning. Physical aspect, any form that takes, only when is converted into symbols or signs that some people assign meaning on it (see Figure 1). There are no symbols or signs which only be a sign or mark near the person (Madanipour, 2010).

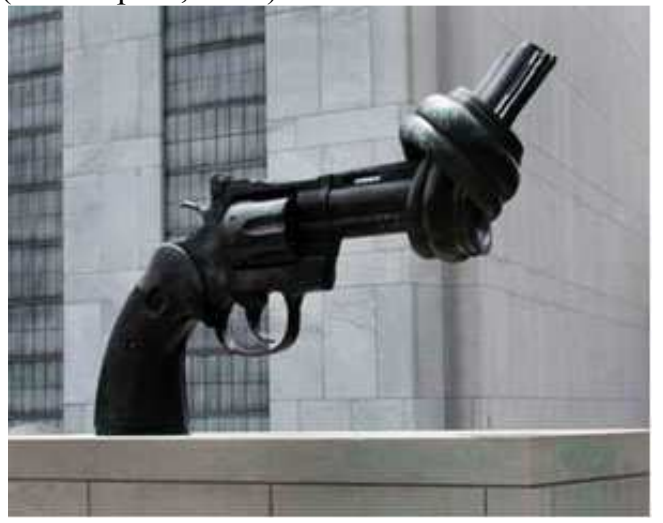

Figure 1. The physical manifestation of meaning and symbol as an urban sculpture - Source: www.zibasazi.ir

\section{Urban Sculpture: Identity, Meaning, Value}

Urban sculpture is among the important physical factors which urban designers can use them to help the human and social manifestation. This statues can be analyzed from several perspectives and context. Goal is the first point. This means that the purpose of designing and implementing an urban sculpture is to realize one of human values. Memories and flashbacks, or sign of a tradition, culture and faith are more important for a man or orientation to modern art. The public perception should be considered or art generalities and modernization. The identity and tradition should present values in the form of tradition or modernity? (Figure 2).

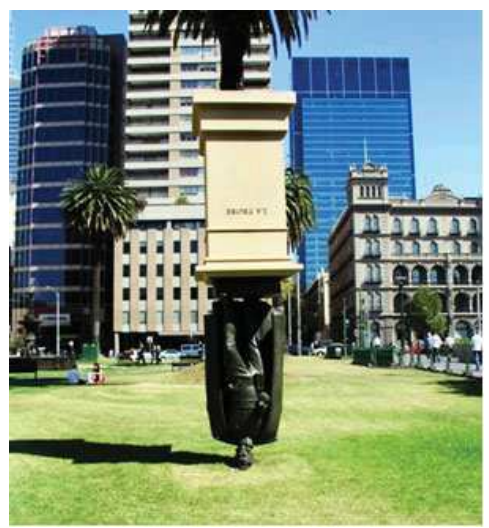

Figure 2. The identity and tradition should present values in the form of tradition or modernity? - Source: www.zibasazi.ir

The relevant location is the first thing which should be considered in applying statues in the city. Sculpture in the right place can be used as an element for the creation of beautiful or special meaning for citizens. Other features of urban sculpture are compatibility with the surrounding environment and closeness to cultural atmosphere, considering principles and fundamentals of the visual arts, understanding the relationship between space and volume 
and its close relationship with the installation place and location, emphases on national and cultural characteristics and paying attention to the aesthetics of the sculptor, valuing the arts and supporting the artists by municipal authorities and using the art of indigenous sculptors of any region, all are other requirements that must be emphasized (Mazinani, 2007) (Fig. 3).

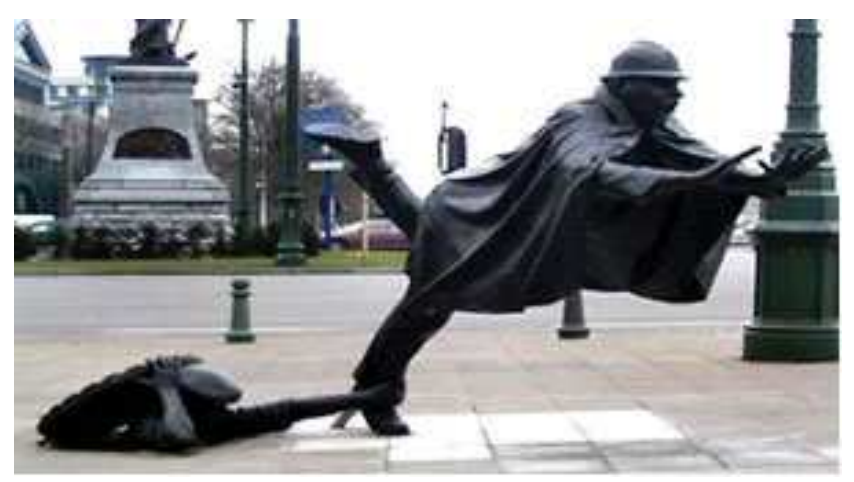

Figure 3. Location of urban sculpture in order to convey the structural and urbanism meaning - Source: www.zibasazi.ir

Sculpting over painting (Which is generally limited to inner speech) is the art of the masses (Moor, 2001). Urban sculpture is a three-dimensional volume with artistic form and expression which is seeable in many different aspects. Sculptures' main function is deportation, identity or transmitting a message to the visitor. Urban sculpture has different visitors, in a way that illiterate people are looking at these volumes. Thus literacy is an important factor in the transmission and reception of meaning in urban sculptures. Urban sculpturing is the common work of sculptors, urban designers, landscape designers and urban planners that is done by the support and guidance of urban managers. The aim of this cooperation beside of the functional considerations, is to create most visual pleasure for observers (Saidi,2008).

In fact, the art of sculpture, to the extent that provides a basic definition about the nature of public space, with all the power induces it to citizens' awareness that don't have any recognition about their environment and its rapid changes and by general mobilization, establishes city's emotional reactions as a common property which requires protection against penetration of malfunctions. Thus, public space is discovered to a realm for discovering identity and in the shadow of some historic landmarks it can reduce the pressures of modern life or show some modernity aspects of historical and cultural landmarks in a new way (Fig. 4).

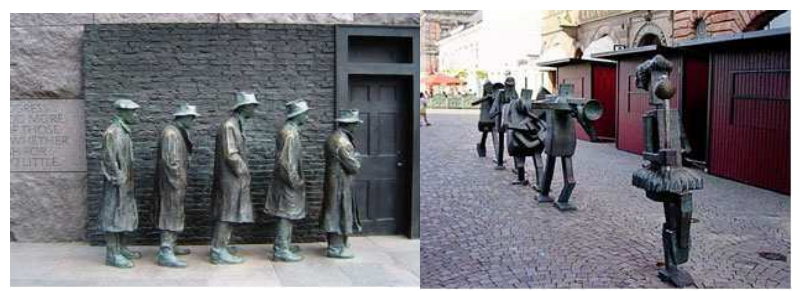

Figure 4. Examples of different types of urban sculpture-Source: www.zibasazi.ir

\section{Discussion and Conclusion}

Urban landscape is the art of giving a visual integration and structure to buildings, streets and spaces that make up the city environment as a combination of artificial and natural spaces and this composition generally tries to inspire a certain sense of meaning and identity. In order to achieve this goal, a variety of techniques and methods may be used that one of the most important are the methods and tools of urban sculpture which the same urban statues, depending on the context, need, site and design planning can play a role in the representation of its meaning in different ways. This role can be held in the form of tradition, modernity, and realism, abstract, conceptual or a quite simple shape and form and play its role in establishing or changing the identity, culture and meaning. The results show that urban sculpture has the major visual and meaning impact to induce meanings and identity of a society and a city and by applying an accurate planned designing and implementing, it is possible to show respect for human and society values in a city through urban sculpture.

\section{References}

[1] Bahraini, H. "The process of urban design," University of Tehran Press, No. 4, 2008.

[2] Ghasemi, M, "Where we come from? Rozaneh Publication, Tehran, 2004.

[3] Lynch, K. "The Image of the City", The MIT Press and the President and Fellows of Harvard College, Massachusetts, 1960.

[4] Madanipour, A. "urban spaces design" concept and urban semiotics, Rozaneh Publication, 2010.

[5] Majedi, H, Zarabadi, Z, "Essay on urban semiotics" Armanshahr Journal, No. 4, summer 2010

[6] Mazinani, F. "Urban sculptures, ugly, beautiful, undecided" Journal for Municipalities, 2007.

[7] Moor, H. "Sculpting the Twentieth Century", Yale University Press, 2001.

[8] Poor Asgharian, M, "Sculpturing in urban spaces of Iran" Neagareh Research Analytic Journal, 8, and 9; autumn and winter 2008 and 2009.

[9] Purmand, HA, Musa Vand, M. "Sculpturing in urban spaces "Journal of Fine Art, Issue 44 - winter 2011

[10] Saidi Ramezani, N, "sculptures bring art to the people," Tandis Journal, No. 2, 2008.

[11] Sajjadi, R. "Can art challenge architecture?" urban spaces 88 , 2002

[12] Sattari, A. "National and cultural identity "Kabir Publication, Tehran, 2003.

[13] Verlag, G.H. "Contemporary sculpture, projects in Munster", Edited by: Klaus Bubmann, Published by Hatje Cantz Publishers, 1997. 